[issue] 16(3)

[category] Original Research

[title] The Landscape of the 'Spirit of Sport'

[subtitle] A Systematic Review

[author(s)] Mojisola Obasa; Pascal Borry

[author details]

\title{
M. Obasa
}

Centre for Biomedical Ethics and Law, Department of Public Health and Primary Care, KU Leuven, 3000. BELGIUM

e-mail: mojisolaobasa@gmail.com

\section{P. Borry [corresponding author]}

Centre for Biomedical Ethics and Law, Department of Public Health and Primary Care, KU Leuven, 3000. BELGIUM.

e-mail: pascal.borry@kuleuven.be

\begin{abstract}
The World Anti-Doping Agency (WADA) sets out a detailed description of what its own conception of the "spirit of sport" as employed in the World Anti-Doping Code (WADC) entails. However, controversies as to the significance and meaning to be ascribed to the term abound in the literature. In order to unravel the core of the debates and to move discussions forward, the authors aimed at reviewing understandings of the spirit of sport in the conceptual literature. The main databases were searched using relevant keywords. After the inclusion and exclusion criteria were applied, eighteen publications were included in the review. The most striking result to emerge from the data is the multivalence of the concept of spirit of sport. Our thematic analysis generated the contestability of the spirit of sport as the predominant theme in the conceptual literature. There is a need for empirical research to generate data about perspectives on the spirit of sport from other stakeholders especially those of the athletes themselves.
\end{abstract}

Keywords Anti-doping; Spirit of sport; Anti-doping policy; Performance enhancement

\section{Introduction}

We can think of the "Spirit of Sport" as something which is felt and immediate-a shared emotion and enthusiasm. We can also think of it as a basic framework of ideas 
or a perspective of understanding which is held in relation to sport. (Molloy and Adams 1987, p. 1)

As part of its mandate to ensure a doping-free sports environment, the World Anti-Doping Agency (WADA) produced the first iteration of the World Anti-Doping Code (WADChereinafter referred to as the Code) in 2003. The Code has since been revised twice. The latest version came into force on January 1, 2015 and is supported by five international standards that ensure a uniform approach to anti-doping around the world.More than 120 countries are signatories to the Code and have established National Anti-Doping agencies. Apart from the Code, WADA also publishes an annual list of prohibited substances. In the preamble to the 2015 Code, as with the previous versions, WADA sets out what it calls the "Fundamental Rationale" for anti-doping programs as seeking "to preserve what is intrinsically valuable about sport," and refers to this intrinsic value as the "the spirit of sport" (WADA 2015).

According to the Code:

The "spirit of sport" is the essence of Olympism, the pursuit of human excellence through the dedicated perfection of each person's natural talents. It is how we play true. The spirit of sport is the celebration of the human spirit, body and mind, and is reflected in values we find in and through sport, including: Ethics, fair play and honesty; Health; Excellence in performance; Character and education; Fun and joy; Teamwork; Dedication and commitment; Respect for rules and laws; Respect for self and other Participants; Courage; Community and solidarity (WADA 2015).

The rationale concludes with a declaration that "Doping is fundamentally contrary to the spirit of sport" (WADA 2015). It is therefore manifest that what this spirit of sport encompasses is very crucial to the very existence of anti-doping policy ab initio. The wording of the rationale has mostly stayed constant since the inception of the code. However, a subtle difference between the "Fundamental Rationale" contained in the latest 2015 WADC and the earlier 2003 and 2009 Codes respectively is noteworthy. The 2015 code adds the phrase "the pursuit of human excellence through the dedicated perfection of each person's natural talents" to the wording of the rationale. The 2015 code also substitutes the phrase "characterized by the following values ..." as contained in the earlier 2003 and 2009 Codes, with the new phrasing of "reflected in values we find in and through sport." 
Furthermore, within the substantive part of the Code itself, a substance or method shall be considered for inclusion on the Prohibited List if WADA, in its sole discretion, determines that the substance or method meets any two of the following three criteria as laid out in Article 4.3.

4.3.1 A substance or method shall be considered for inclusion on the Prohibited List if WADA, in its sole discretion, determines that the substance or method meets any two of the following three criteria:

4.3.1.1 Medical or other scientific evidence, pharmacological effect or experience that the substance or method, alone or in combination with other substances or methods, has the potential to enhance or enhances sport performance;

4.3.1.2 Medical or other scientific evidence, pharmacological effect or experience that the Use of the substance or method represents an actual or potential health risk to the Athlete;

4.3.1.3 WADA's determination that the Use of the substance or method violates the spirit of sport described in the introduction to the Code (WADC, 2015).

This spirit of sport clause appears again in Article 18.1 (education) and 18.2 (programmes and activities) headings of the Code.

However, even though WADA sets out a detailed description of what its own conception of the spirit of sport as employed in the Code entails, this has not been enough to forestall controversy as to the significance and meaning to be ascribed to the term in the literature. For example, on the one hand, the spirit of sport has been said to be too vague and unclear to underpin anti-doping policy (Heane, Koh, and McDermott 2013), while on the other hand, scholars such as Loland and Hoppeler $(2012,352)$ posit that this said "vagueness" can be operationalized. Thus, this spirit of sport rationale has been subject to varied interpretations and philosophical debates (Beamish and Ritchie 2006; Henne, Koh, and McDermott 2013; Loland and Hopeler 2012; McNamee 2012, 2013; Waddington et al. 2013). The literature is replete with several calls to either maintain (McNamee 2013; Kornbeck 2013), modify (Loland and Hoppeler 2012), or outrightly discard (Heane, Koh, and McDermott 2013; Savulescu, Foddy, and Clayton 2014) the concept. Despite the fact that several contrasting arguments, opinions, and viewpoints have been posited in the past decade regarding the proper conception, if any, of WADA's spirit of sport (de Hon 2017; Geeraets 2017; 
Bloodworth and McNamee 2017), this heated debate persists in the literature and seems to have no resolution in sight.

The controversy about the continued presence of the spirit of sport clause in the Code has been so raging that it is reported that an earlier draft of the 2015 iteration had seen significant changes in the way in which the clause was to serve as a criterion under Article 4.3 of the code. (Mcnamee 2012; Kornbec 2013). Nevertheless, the status quo was maintained which shows how pivotal the spirit of sport is to the Code's architecture.

In as much as the spirit of sport notion continues to be the prima facie cornerstone justification for anti-doping worldwide (Kornbeck 2013), a full comprehension of how WADA's spirit of sport is understood in the literature is vital not only to unravel the core of the debates, but also to move the conversation forward. This is especially important as discussions are currently ongoing regarding the 2021 version of the Code. This work thus aims to be the first cumulative aggregation and analysis of the several elucidations of the spirit of sport clause since the coming into force of WADA's first. Therefore, the objective of this study is to systematically review how the spirit of sport clause, rationale, and criterion is understood and discussed in the literature.

\section{Methodology}

Design

The methodology used for this study was a systematic review. To improve the reporting of the search process, we used the preferred reporting items for systematic reviews and metaanalyses (PRISMA) statement (Liberati et al. 2009).

\section{Study Selection}

The relevant electronic databases chosen included Web of Science, Science Direct, PubMed, SPORTDISCUS, Philosopher's index and MEDLINE. Additional searches were performed in the more general database Scopus to capture any missing resource. Finally, the first $\mathrm{t}$ results from Google Scholar were also screened. In addition to the conducted database searches, ancillary searches were performed by snowballing from the reference list of the identified authors.

\section{Search Strategy}

The Boolean string ("spirit of sport") AND (doping) was applied in the mentioned databases. Given the very specific scope of the question and the intention to capture all possible data on the concept of spirit of sport, no restrictions or filters were placed in the databases. After 
duplicates were removed, all returned items were screened by title and abstract. After this initial screening, selected articles were read and the eligibility criteria was applied. Efforts were made to get full text of all articles.

\section{Inclusion and Exclusion Criteria}

Initial screening of title and abstract was conducted from the filtered reference list using predetermined inclusion and exclusion criteria.

As the focus of this systematic review is on conceptual argumentative contributions to the discussions on the spirit of sport, we excluded publications that reported on empirical studies. Publications were selected for inclusion and analysis if they met the following inclusion criteria:

(1) Must be published in a peer review journal or in a WADA magazine

(2) Must be written in English

(3) Must either significantly discuss, analyse, criticize, or support the concept of the spirit of sport as contained in the WADC

(4) Must specifically address the concept in the context of anti-doping policy

(5) Must not merely mention the notion of spirit of sport

(6) Must not merely repeat existing arguments in the literature without offering own perspective, conception or opinion

Title, abstract and full-text screening were performed by the first author (MO). The second author (PB) acted as determiner in case of uncertainty. The search was conducted between March 1, 2018, and the April 1, 2018.

\section{Data Extraction and Synthesis}

Data extraction took the form of a thematic analysis (Nowell et al. 2017). Quotes were retrieved from articles, which were in turn coded. We did not interpret the data, but followed the authors' understandings of the concept of the spirit of sport. To reduce complexity of the resulting list, summary categories were developed inductively from the data using a conventional approach to qualitative thematic content analysis method (Hsieh and Shannon 2015).

\section{Results}

The outline of the literature search is presented according to the PRISMA flowchart below (figure 1). From the initially identified 332 references, we finally included fifty-six 
publications covering discussions on the spirit of sport. For the above-described reasons we further excluded thirty-eight publications from the in-depth analysis (see the flowchart in figure 1). The following results therefore represent the remaining eighteen publications. Table 1 presents all references for the included publications.

Our thematic analysis demonstrates a plethora of arguments in favour of and in opposition to the spirit of sport clause at the level of meaning, functionality, and applicability, as well as the implication of the clause in the Code. In order to do justice to the richness of nuance contained in the literature and to ensure clarity regarding the central theme of contestability of the concept, we present the following subthemes and subcategories that were identified:

- The spirit of sport and the Olympic tradition

- The spirit of sport as an instrumental construction

- Conceptual (im)precision of the spirit of sport

- (In)applicability of the spirit of sport

It should be noted, however, that these sub-themes do not have fixed boundaries and sometimes overlap and dovetail into one another because of the overarching multivalence of the spirit of sport concept itself.

The Spirit of Sport and the Olympic Tradition In the literature, divergent opinions were expressed regarding the spirit of sport and the association of the concept to the Olympic tradition. On one hand, perspectives that align with the formation of the Code's portrayal of Olympism as virtuous deemed this association as lending credence to the validity of the spirit of sport as a concept. For example, one author expressed that, "I understand the spirit of sport to be embodied not only in the Olympic Games [...] I believe the spirit of sport, and the Olympics, can and should survive" (Murray 2007).

On the other hand, arguments were put forward that the spirit of sport clause's alignment with Olympism by its reference to the "Olympic essence" is a continuation of the Olympic tradition, which is itself based on mythology (Ritchie 2014; Henne, Koh, and McDermott 2013). The argument goes thus:

WADA's Code reflects Coubertin's legacy perfectly, defending anti-drug rules based on the "intrinsic value [of] 'the spirit of sport."” But such notions, it should be realized, are as sociologically and historically vacuous as we now know Coubertin's to have been a century ago. First, as has been shown here, even if 
only briefly, the ideal of "pure" Olympic sport was fabricated right from the start. To believe in such an ideal is to believe in historical mythology (Ritchie 2014). Arguments about the spirit of sport as an ideal also followed the lines of viewing the concept as aspirational, archetypical, and emblematic on the one hand, whilst utopian, superfluous, and phantasgomoric on the other hand (Tamburrini 2007; Geeraets 2017; McNamee 2013, 2013; Gleaves, Llewellyn and Lehrbach 2014). The quote below illustrates this:

...we cannot understand the notion as a mere description of sport, but rather as an ideal...the values and virtues listed characterize sport at its best: this is what we ought to aim for: these are the positive things that have defined sports at their best since their modern re-invention and institutionalization in the 19th century.....and that is why the spirit of sport is an ideal worth defending and retaining at the heart of anti-doping policy. (McNamee 2013)

A contrasting view was expressed thus; "More problematic, treating the spirit of sport as a fuzzy ideal ignores the historicized nature of performance enhancement and technology ..." (Gleaves, Llewellyn, and Lehrbach, 2014).

The Spirit of Sport as an Instrumental Construction Various authors described the spirit of sport concept as a product of active construction, deliberately crafted to serve predetermined purposes, thereby stripping it of its supposed transcendental elements (Ritchie 2013; Waddington et al. 2014; Mulhall 2006; Geeraets 2017; Kornbeck 2013; Henne, Koh, and McDermott 2013) In the literature, this instrumentalization argument is backed up by an incursion into the surrounding circumstances at the inception of the Olympic Games. Arguments were advanced to the effect that the images of grandeur, universalism, and purity associated with the Olympic movement in the nineteenth century were actively constructed by the founder, Pierre de Coubertin, to serve purposes specific to that age. (Ritchie 2013, 2014; Henne, Koh, and McDermott 2013)

Following the same line of argumentation, it was suggested that just as Coubertin created this powerful Olympic imagery, the drafters of the Code also actively constructed the spirit of sport clause. As one author put it:

... an inherent "spirit" of sport did not pre-exist in the "nature of sport" as it were: rather, those involved with the creation of WADA's Code had to actively create "sport's spirit" as a problem-solving measure in light of the immediate issues facing them and in light of the latest crisis occurring in sport. A "catch all" 
phrase was needed to deal with practical issues at play and to warrant inclusion of substances on the banned list in particular, and the result was the active construction of the "Spirit of Sport." (Ritchie 2013)

Accounts tracing the historical origins of the spirit of sport clause postulated that the spirit of sport clause was employed as an instrumentation to deliberately propagate a pre-set agenda through the Code (Ritchie 2013, 2014; Waddington et al. 2014). It was suggested by some commentators, that such purposes include, inter alia, the inclusion of non-performance enhancing substances on the Prohibited List and the insulation of WADA from outside scrutiny and criticism (Kornbeck 2013; Wadddington et al. 2013; Mulhall 2006).

Furthermore, the argument was advanced that WADA deliberately uses the spirit of sport to extend its power beyond the normal bounds of the sporting realm to serve interests such as public health concerns. Consequently, the inclusion of cannabinoids on the prohibited list is deemed to be at the instance of the spirit of sport clause (Ritchie 2013; Savulescu, Foddy, and Clayton 2004; Waddington et al. 2013; Henne, Koh, and McDermott 2013; Geeraets 2017) The following quotation shows this position:

WADA has clearly used the "Spirit of Sport" argument to reach beyond the traditionally accepted sporting concerns. In this regard, it is clear that WADA's third criterion for inclusion - that use of drugs is against the vaguely define "Spirit of Sport"- [...] provides an argument for banning recreational drugs whose use cannot be banned on grounds of performance enhancement.

(Waddington et al. 2013)

Similarly, arguments were advanced that WADA's capabilities, through the presence of the spirit of sport clause as a criterion, facilitates the possibility of being held to a non-evidencebased standard in making a determination about whether or not a doping violation may have occurred (Henne, Koh, and McDermott 2013; Waddington et al. 2013; Ritchie 2013; Kornbeck 2013; Geeraets 2017).

Conceptual (Im)Precision

The most recurring description of the spirit of sport clause in the literature is that it is unclear. The majority of included articles expressly used the word "vague" to describe the spirit of sport clause both as a rationale and as a criterion. Arguments advanced in the literature contend that the words that the Code employs to portray the spirit of sport are not in themselves strictly monosemous; therefore, when the values are taken together, no distinctive clear-cut meanings can be ascribed to the spirit of sport clause (Waddington et al. 2014; 
Carolan 2006; McNamee 2012; Geeraets 2017; Kornbeck 2013; de Hon 2017; Mulhall 2007; Loland and Hoppeler 2012). The following quote illustrates: “... the "Spirit of Sport" is not really defined in the Code, but rather illustrated: however, the concepts used to illustrate it are often very general ...” (Kornbeck 2013).

The literature revealed that the question is highly polarised as to what the effect of this socalled vagueness is on the interpretation and applicability of the spirit of sport clause as a criteria and rationale for anti-doping policy. Opinions varied as to whether or not the spirit of sport clause is rendered practicable or impracticable by virtue of its "imprecision" and whether or not the so called "imprecision" is benign or malign. There are viewpoints that contend that the lack of precision of the spirit of sport is not necessarily problematic and does not affect its ability to be meaningful and functional within the context of the Code (Carolan 2006; de Hon 2017; McNamee 2012, 2013; Gleaves, Llewellyn, and Lehrbach 2014). The quote below illustrate this point:

It strikes me that the Spirit of Sport criterion is exactly what ADP needs ... the world of natural languages is not really split into two categories: the neat and the vague. Granted, some concepts are clearer than others. It is true that WADA's list is neither a definition nor an analysis ... It is simply a list of values widely referred to in relation to an ideal of sports and participation therein. But we handle conceptual vagueness every day without remarking upon it. When does yellow shade into ochre, or orange; or when does pink become cerise? Even colour predicate is conceptually vague, but we do not hear of the abandonment of colour-words. How could we? (McNamee 2012)

A disparity was observed amongst authors regarding how the spirit of sport clause is to be understood and interpreted. Some authors contend that the spirit of sport is an "open concept" (McNamee 2012), “is open for philosophical debate” (Malloy, Kell, and Kelln 2007), or "should indeed be read at face value"(Kornbeck 2013).

Following the above viewpoint, paradoxical to the Code's reference to Olympism and the declaration that "doping is contrary to the spirit of sport," there were some suggestions that doping may not in fact violate the spirit of sport but may rather be an expression/exemplification of the concept. For example:

... banned doping substances and techniques are therefore obviously in accordance with the "spirit" of today's crudely competitive and highly technified 
sports world, as they have everything to do with the essential purpose of athletic contest: to expand the limits of our capabilities. (Tamburrini 2006)

In contrast, another viewpoint held that the openness of the concept does not mean that every possible conclusion that may be reached by a reading of the spirit of sport clause should be reached. The argument goes thus:

... when people simply assert that what the spirit of sport means is simply a subjective matter, they are simply wrong. One cannot move from the fact that there is an open-texture to the concept so that there are genuine disputes about its meaning, to the conclusion that everyone has their own concept, which is as valid as the next person's. (McNamee 2013)

Arguments were advanced to the effect that the spirit of sport clause, when read together as a rationale and as a criterion, amounted in parts to tautology and circularity (Waddington et al. 2014; Mullhall 2006; Carolan 2006; de Hon 2017; Mcnamee 2013; Geeraets 2017) Similarly, it was suggested that the wording of the rationale refers to the rationale itself to lend credence to its contents, which ultimately means the argument actually starts with what it ends with. Specific examples that support this view point were given especially in relation to some of the values, such as "health" and "excellence in performance" as shown below:

[...] the "Spirit of Sport" includes "health" as one of its 11 descriptors, resulting in the Paradox that if a drug or method is considered unhealthy it in itself meets two of the three criteria. (Waddington et al. 2013)

it does not help that the "Spirit of Sport" is explained using, among other words, "excellence in performance" and "health", and as such it redirects to the other two criteria. (de Hon. 2017)

One of the key observations from the literature was the suggestion that the spirit of sport clause making its way as a criterion under the two of three rule amounts to a redundancy (de Hon 2017). In this view, since the spirit of sport clause is integral to the Code's make-up, in that the spirit of sport is provided as the "Fundamental Rationale" for the existence of the Code in the first place, there is invariably the presupposition that it is through this lens of the spirit of sport that all the provisions of the Code is to be seen. Therefore, it was suggested that the presence of an optional spirit of sport criterion is not only pointless but serves to undermine the pervading coverage of the spirit of sport as the bedrock upon which the code in its entirety rests (de Hon 2017). As one author puts it: 
If the concept is fundamental to the prohibition of doping, and it probably is, it is redundant to offer it as a potential one-out-of-three criterion at a later stage. First of all, it is superfluous to repeat the same argument twice (although this is not necessarily problematic in itself) and secondly, this opens the door to formally prohibit substances or methods that are not considered to be in breach of the "Spirit of Sport" which is strange considering the central role of this concept in the entire WADC. (de Hon 2017)

(In)Applicability of the Spirit of Sport

Arguments were presented both for and against the ability and capability of the spirit of sport to guide, demarcate, and specify which substances should be banned (on the Prohibited List) on one hand, and whether the spirit of sport can do so in a methodological manner which can be standardized, which is consistent, and which is not arbitrary (Mcnamee 2012, 2013; Kornbeck 2013; Geeraets 2017; Henne, Koh, and McDermott 2013; de Hon 2017; Mulhall 2016; Loland and Hoppeler 2012; Waddington et al. 2013; Murray 2007). It was suggested that the spirit of sport clause can barely be functional and utilized when deciding on placing a particular substance on the Prohibited List (Geeraets 2017; Kornbeck 2013; Mulhall 2006; Gleaves, Llewellyn, and Lehrbach 2014). The contention raised here is that there is a lack of specificity as to how the spirit of sport clause can be utilized to draw the line exactly between banned substances and methods, and others. The following quote illustrates this:

[...] the spirit-of-sport ideal can only work looking backward, once the substance list is set and the ideals defined. It cannot work looking forward. It cannot tell us why a new innovation like waxing skis is or is not contrary to its ideal. More to the point, it cannot tell us if blood transfusions are more akin to steroids or to ski wax. (Gleaves, Llewellyn, and Lehrbach 2014)

Furthermore, the view was expressed that the so-called inapplicability of the spirit of sport clause both as the rationale and criterion for anti-doping policy was deliberately in WADA's interests, as it serves to provide a facade of forthrightness. (Geeraets 2017)

From WADA's perspective, however, the inapplicability of the criteria is not a problem, but rather the point of the enumeration in that it aims to create an impression of justice, while not actually being committed to a standard of justice. So, the values' general inapplicability serves a dual purpose: on the one hand, WADA may claim that the Code is about serving justice, while, on the other hand, it can classify non-performance-enhancing substances such as cannabis as 
doping and adopts standards of strict and vicarious liability which—in other contexts - are generally considered to be contrary to justice. (Geeraets 2017) Various authors argued that without this ability to be distinctive and distinguishable as a yardstick or formula, employing the spirit of sport clause to demarcate substances amounts to arbitrariness, inconsistency, contradiction, and absurdity (Geeraets 2017; Kornbeck 2013; Mulhall 2006; Henne, Koh, and McDermott 2013). For example:

$[\ldots]$ the lack of clarity around its definition makes its application particularly problematic, because it is largely left to subjective interpretation. This conundrum has far-reaching effects on decisions regarding whether or not to include illicit drugs from WADA prohibited list. (Henne, Koh, and McDermott 2013)

In contrast, various authors also argue that the concept is adequate to make a determination of what substances should be on the prohibited list (Mcnamee 2012, 2013; Murray 2007; Kornbeck 2013). It is suggested that whatever deficiencies that are perceived with regards to the application of the spirit of sport should not be attributed to the clause in itself but to the lack of openness regarding the usage of the clause (Mcnamee 2013). Another argument takes the view that the fact that it may indeed be difficult to draw demarcating lines using the spirit of sport criterion is not tantamount to discarding the clause (Murray 2007). The following quotations provide an illustration:

If we want to argue that there are some ways for preparing for and competing in sports that threaten the (contested) ideals that it stands for, we must have some mechanism by which this is done. A spirit of sport criterion is thus essential to the task of determining which substances and methods are thought of as acceptable or not. (Mcnamee 2012)

The line must be drawn with great care, and there will always be those cases that challenge it: those cases should prompt a thoughtful reappraisal of precisely where to draw the line- but difficult cases are never reasons to abandon linedrawing altogether. (Murray 2007)

Divergent arguments were also put forward in the literature about whether or not the process of the application of the spirit of sport clause is truly transparent (McNamee 2012, 2013; Kornbeck 2013; de Hon 2017), whether the sanctions based on the application of the clause were legitimate (Mulhall 2006; Carolan 2006; Kornbeck 2013, Geeraets 2017) and if there was accountability within the entire process (Kornbeck 2013; Geeraets 2017; de Hon 2017). The quotes below illustrate this viewpoint: 
What is needed then, is not an objection on the grounds of vagueness, or linedrawing, but a proper account of goods and virtues that sports ideally instantiate and then an account of why some will fall under the heading "doping" while others will not. (McNamee 2012)

Without openly encouraging arbitrariness, the "Spirit of Sport" nevertheless provides a perfect discursive and procedural platform for it. This is bound to have implications at the level of transparency and accountability and the ability to limit the exercise of power. (Kornbeck 2013)

Furthermore, it was suggested that the objections raised against the spirit of sport clause could be addressed in a sounder manner, if the governance mechanism were more open and transparent (McNamee 2012, 2013; de Hon 2017). The following quote depicts this phenomenon:

What seems clear to me, is that it is not the Spirit of Sport that is the problematic "catch all" rule. It does seem, however, that no guidance is set out for the employment of this rule. But then there appears to be a lack of transparency about how any mechanism is employed in the construction of the PL. (McNamee 2012)

\section{Discussion}

The objective of this study was to systematically review how the spirit of sport clause, rationale, and criterion is understood and discussed in the literature. Through this analysis of the landscape of the concept of spirit of sport, we found various conceptions, meanings, uses, and values attached to this clause. This is reflected by the range of themes which were generated by our analysis, namely:

- the spirit of sport and the Olympic tradition

- the spirit of sport as an instrumental construction

- conceptual (im)precision of the spirit of sport

- (in)applicability of the spirit of sport

Our systematic review also revealed that although the spirit of sport clause is of interest to several authors, the majority of publications did not offer a particularistic basic or simple answer to the question of what, in the authors' opinion, the spirit of sport really is. Interpretations of the spirit of sport appear to exist on a spectrum. Our findings suggest that the major bone of contention seems to be with regards to how the spirit of sport is to be used as a criterion and not so much about its presence as the fundamental rationale. This should 
not be taken to mean that the spirit of sport as a rationale does not have disputations surrounding it, but rather it appears that the objections to the concept of the spirit of sport as the rationale for anti-doping policy, on the whole, was met with less criticism than as a criterion under the two-out-of-three rule for determining which substances and methods are to be placed on the prohibited list. Savulescu, Foddy, and Clayton (2004), Mulhall (2006), Tamburrini (2006), Henne, Koh, and McDermott (2013), Waddington et al. (2013), Kornbeck (2013), Geeraets (2017) and de Hon (2017), to mention a few of our included articles, all expressed the view in one way or another that the spirit of sport clause as a criterion was inadequate and unfit for purpose in its current form in the Code.

Remarkably, however, this conclusion was sometimes reached from different starting points. To illustrate, Geeraets (2017) argues vehemently against the spirit of sport clause both as the fundamental rationale and as a criterion in the Code. However, upon closer scrutiny, Geeraets' perspective seemed to mellow and appeared to envision the spirit of sport clause as being applicable when read in conjunction with the first criterion. Whereas, on their part, Waddington et al. (2013), who are also opposed to the spirit of sport clause, prefer total obliteration of the clause from the code's architecture. On the other hand, de Hon (2017) who argues favourably for the spirit of sport as a rationale, suggests also that it be expunged as a criterion. However, the reasons de Hon proffers are diametrically opposed to those of Waddington et al. According to de Hon (2013):

... if the "Spirit of Sport" criterion was to be removed from prohibited list-related discussions [it will lead] to more profound discussion on what substances and methods should be prohibited in sport, all encircling a core concept being a clear admiration for the spirit of sport. (de Hon 2013)

Furthermore, while McNamee (2012) appears to lend unwavering support to the spirit of sport clause both as a rationale and criterion, a close observation reveals that the degree of support seems to be less equivocal and appears to diminish somewhat for the spirit of sport as a criterion in its current form. These subtleties further demonstrate the multivalence of standpoints, which in turn leads to varied conclusions, regarding the favourability or not of the concept of the spirit of sport in the architecture of anti-doping policy. The importance of these differences of perspectives and perceptions of the spirit of sport as the fundamental rationale and as a criterion carries a more nuanced message than immediately appears. As such, any discussion regarding the subject of the spirit of sport clause would do good to take 
this into account and to be specific about which of the readings of the spirit of sport concept — rationale or criterion—is being addressed.

The extent to which its so-called imprecision undermines the spirit of sport clause was contended amongst our sample, yet what we found very striking in an otherwise contested debate is the absolute unanimity when it came to the demand for more transparency and accountability (Mulhall 2006; Carolan 2006; McNamee 2012, 2013; Kornbeck 2013; Waddington et al. 2013; Geeraets 2017; de Hon 2017). In particular, various authors referred to the need for checks and balances (Kornbeck 2013; McNamee 2012) and the need to provide more clarity on the way decisions are made, ratio decidendi (McNamee 2012; Kornbeck 2013; de Hon 2017).

Our findings should be understood in the context of the following limitations. First, our systematic review was predominantly based on articles from peer-reviewed journals, potentially leaving out some relevant publication on this issue. Secondly, many of the included articles were written prior to the coming into force of the 2015 code. Of the three articles that were written after the latest version of the code came into force (Savulescu 2016; de Hon 2013; Kornbeck 2013), only one (Savulescu 2016) touched on the issue of "natural" as introduced by the new wordings of the rationale. However, the elucidation offered, fell short of addressing the specific issue of "natural talents" as contained in the code. Therefore, it remains unknown whether or not the subtle but significant changes in the wording of the rationale since 2015 might have made a difference in the argumentations contained in the literature. Thirdly, a publication bias might affect the academic literature as it might be that opponents of the concept more expressively developed their views than advocates of the concept.

Despite these stated limitations, our analyses nevertheless yielded useful insights into the variety of philosophical, ethical, legal, organizational, and societal issues that are prompted by our focused question

\section{Conclusion}

Our review showed the spirit of sport concept as employed in the WADA Code to be a multivalent concept whose understandings exist on a continuum in the literature. This lack of homogeneity at the level of meanings ultimately results in heterogeneous opinions as to the applicability or not of the concept. We also found nuanced and dissimilar understandings of the spirit of sport as a rationale on one hand and as criterion on the other. These subtleties in arguments about the spirit of sport must be taken into consideration in order to have truly 
meaningful discussions about the concept's presence and function in the Code.

Moreover, at the moment, the entire framework of anti-doping policy rests upon the spirit of sport concept. This fundamental fact, thus, makes a thorough apprehension of the concept essential for the purposes of legitimization of anti-doping in general. The views presented in this paper have been those of the experts from the medical, social, legal, and philosophy fields. However, in order to fully understand what the spirit of sport is, if at all it truly exists, perspectives from other stakeholders especially those of the athletes themselves should also be had.

\section{References}

Beamish, R., and I. Ritchie. 2006. Fastest, highest, strongest: A critique of high-performance sport. Routledge.

Bloodworth, A.J., and M. McNamee. 2017. Sport, society, and anti-doping policy: An ethical overview. In Acute Topics in Anti-Doping, edited by O. Rabin and Y. Pitsiladis, 177185.

Carolan, E., 2006. The New WADA Code and the search for a policy justification for antidoping rules. Seton Hall Journal of Sports and Entertainment Law 16(1).

de Hon, O., 2017. The redundancy of the concept of "spirit of sport" in discussions on the prohibited list of doping substances. International Journal of Sport Policy and Politics 9(4): 667-676.

Geeraets, V. 2018. Ideology, doping and the spirit of sport. Sport, Ethics and Philosophy 12(3): 255-271.

Gleaves, J., M.P. Llewellyn, and T. Lehrbach. 2014. Before the rules are written: Navigating moral ambiguity in performance enhancement. Sport, Ethics and Philosophy 8(1): 8599.

Henne, K., B. Koh, and V. McDermott. 2013. Coherence of drug policy in sports: Illicit inclusions and illegal inconsistencies. Performance Enhancement and Health 2(2): $48-55$.

Hsieh, H-F., and S.E. Shannon. 2005. Three approaches to qualitative content analysis. Qualitative Health Research 15(9): 1277-1288. 
Kornbeck, J. 2013. The naked spirit of sport: A framework for revisiting the system of bans and justifications in the world anti-doping code. Sport, Ethics and Philosophy 7(3): 313-330.

Liberati, A., D.G. Altman, J. Tetzlaff, et al. 2009. The PRISMA statement for reporting systematic reviews and meta-analyses of studies that evaluate health care interventions: Explanation and elaboration. PLOS Medicine 6(7): e1000100.

Loland, S. and H. Hoppeler, 2012. Justifying anti-doping: The fair opportunity principle and the biology of performance enhancement. European Journal of Sport Science 12(4): $347-353$.

Malloy, D.C., R. Kell, and R. Kelln. 2007. The spirit of sport, morality, and hypoxic tents: Logic and authenticity. Applied Physiology, Nutrition, and Metabolism 32(2): 289296.

McNamee, M.J. 2013. The spirit of sport and anti-doping policy: An ideal worth fighting for. Play True 1: 14-16.

McNamee, M.J. 2012. The spirit of sport and the medicalisation of anti-doping: Empirical and normative ethics. Asian Bioethics Review 4(4): 374-392.

Molloy, J.W., and Adams, R.C. 1987. The spirit of sport: Essays about sport and values. Wyndham Hall Press.

Moston, S. 2013. The spirit of sport? Performance Enhancement \& Health 2(2): 74-75.

Mulhall, S.J. 2006. Critique of the world anti-doping code. a. Advocate (Vancouver) 64, 29.

Murray, T.H. 2007. In search of the spirit of sport. Play True 3: 24-6.

Nowell, L.S., J.M. Norris, D.E. White, and N.J. Moules. 2017. Thematic analysis: Striving to meet the trustworthiness criteria. International Journal of Qualitative Methods 16(1).

Ritchie, I. 2014. Pierre de Coubertin, doped "amateurs" and the "spirit of sport": The role of mythology in Olympic anti-doping policies. The International Journal of the History of Sport 31(8): 820-838.

Ritchie, I. 2013. The construction of a policy: The World Anti-Doping Code's "spirit of sport" clause. Performance Enhancement \& Health 2(4): 194-200.

Savulescu, J. 2016. Doping scandals, Rio and the future of human enhancement. Bioethics 30(5): 300-303.

Savulescu, J., B. Foddy, and M. Clayton. 2004. Why we should allow performance enhancing drugs in sport. British Journal of Sports Medicine 38(6): 666-670. 
Tamburrini, C. 2006. Are doping sanctions justified? A moral relativistic view. Sport in Society 9(2): 199-211.

World Anti-Doping Agency (WADA). 2015. World Anti-Doping Code 2015. Canada: World Anti-Doping Agency Montreal.

Waddington, I., A.V. Christiansen, J. Gleaves, J. Hoberman, and V. Møller. 2013. Recreational drug use and sport: Time for a WADA rethink? Performance Enhancement \& Health 2(2): 41-47.

Table 1 List of included articles.

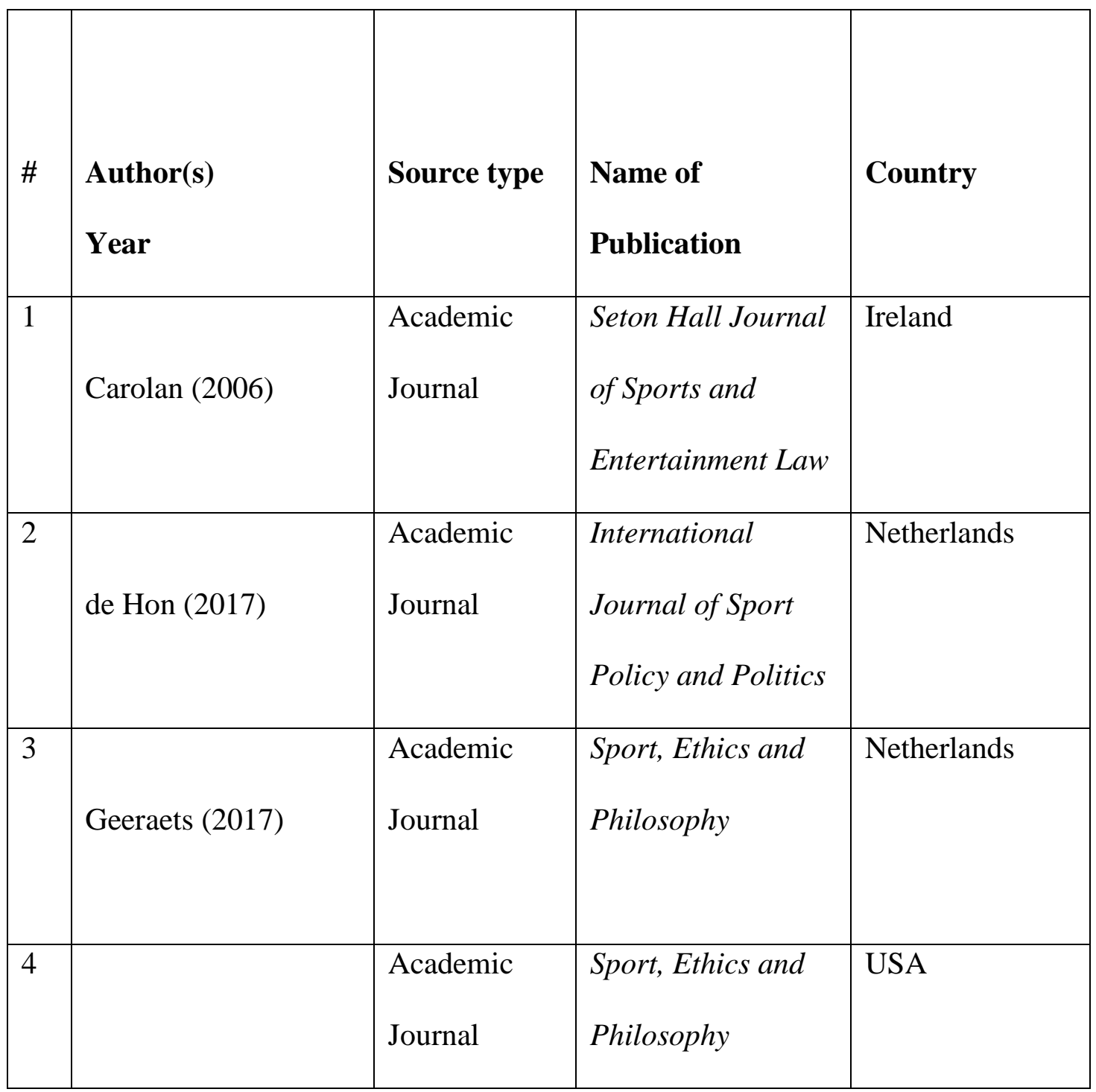




\begin{tabular}{|c|c|c|c|c|}
\hline & $\begin{array}{l}\text { Gleaves, Llewellyn } \\
\text { and Lehrbach (2014) }\end{array}$ & & & \\
\hline 5 & Kornbeck, (2013) & $\begin{array}{l}\text { Academic } \\
\text { Journal }\end{array}$ & $\begin{array}{l}\text { Sport, Ethics and } \\
\text { Philosophy }\end{array}$ & Belgium \\
\hline 6 & Henne, et. al (2013) & $\begin{array}{l}\text { Academic } \\
\text { Journal }\end{array}$ & $\begin{array}{l}\text { Performance } \\
\text { Enhancement \& } \\
\text { Health }\end{array}$ & Australia \\
\hline 7 & $\begin{array}{l}\text { Loland, and } \\
\text { Hoppeller (2012) }\end{array}$ & $\begin{array}{l}\text { Academic } \\
\text { Journal }\end{array}$ & $\begin{array}{l}\text { European Journal } \\
\text { of Sports Science }\end{array}$ & Norway \\
\hline 8 & Malloy et. al (2007) & $\begin{array}{l}\text { Academic } \\
\text { Journal }\end{array}$ & $\begin{array}{l}\text { Applied } \\
\text { Physiology, } \\
\text { Nutrition, and } \\
\text { Metabolism, }\end{array}$ & Canada \\
\hline 9 & Mcnamee (2012) & $\begin{array}{l}\text { Academic } \\
\text { Journal }\end{array}$ & $\begin{array}{l}\text { Asian Bioethics } \\
\text { Review }\end{array}$ & United Kingdom \\
\hline 10 & Mcnamee (2013) & WADA & Play True (WADA) & $\begin{array}{l}\text { United } \\
\text { Kingdom }\end{array}$ \\
\hline 11 & Mulhall (2006) & $\begin{array}{l}\text { Academic } \\
\text { Journal }\end{array}$ & The Advocate & Canada \\
\hline 12 & Murray (2007) & WADA & Play True (WADA) & United States \\
\hline
\end{tabular}




\begin{tabular}{|c|c|c|c|c|}
\hline 13 & Ritchie,I (2013) & $\begin{array}{l}\text { Academic } \\
\text { Journal }\end{array}$ & $\begin{array}{l}\text { Performance } \\
\text { Enhancement \& } \\
\text { Health }\end{array}$ & Canada \\
\hline 14 & Ritchie, (2014) & $\begin{array}{l}\text { Academic } \\
\text { Journal }\end{array}$ & $\begin{array}{l}\text { The International } \\
\text { Journal of the } \\
\text { History of Sport }\end{array}$ & Canada \\
\hline 15 & $\begin{array}{l}\text { Savulescu, Foddy and } \\
\text { Clayton (2004) }\end{array}$ & $\begin{array}{l}\text { Academic } \\
\text { Journal }\end{array}$ & $\begin{array}{l}\text { British Journal of } \\
\text { Sports Medicine }\end{array}$ & United Kingdom \\
\hline 16 & Savulescu (2016) & $\begin{array}{l}\text { Academic } \\
\text { Journal }\end{array}$ & Bioethics & United Kingdom \\
\hline 17 & Tamburrini (2006) & $\begin{array}{l}\text { Academic } \\
\text { Journal }\end{array}$ & Sport in Society & Sweden \\
\hline 18 & $\begin{array}{l}\text { Waddington et al. } \\
(2013)\end{array}$ & $\begin{array}{l}\text { Academic } \\
\text { Journal }\end{array}$ & $\begin{array}{l}\text { Performance } \\
\text { Enhancement \& } \\
\text { Health }\end{array}$ & Norway \\
\hline
\end{tabular}




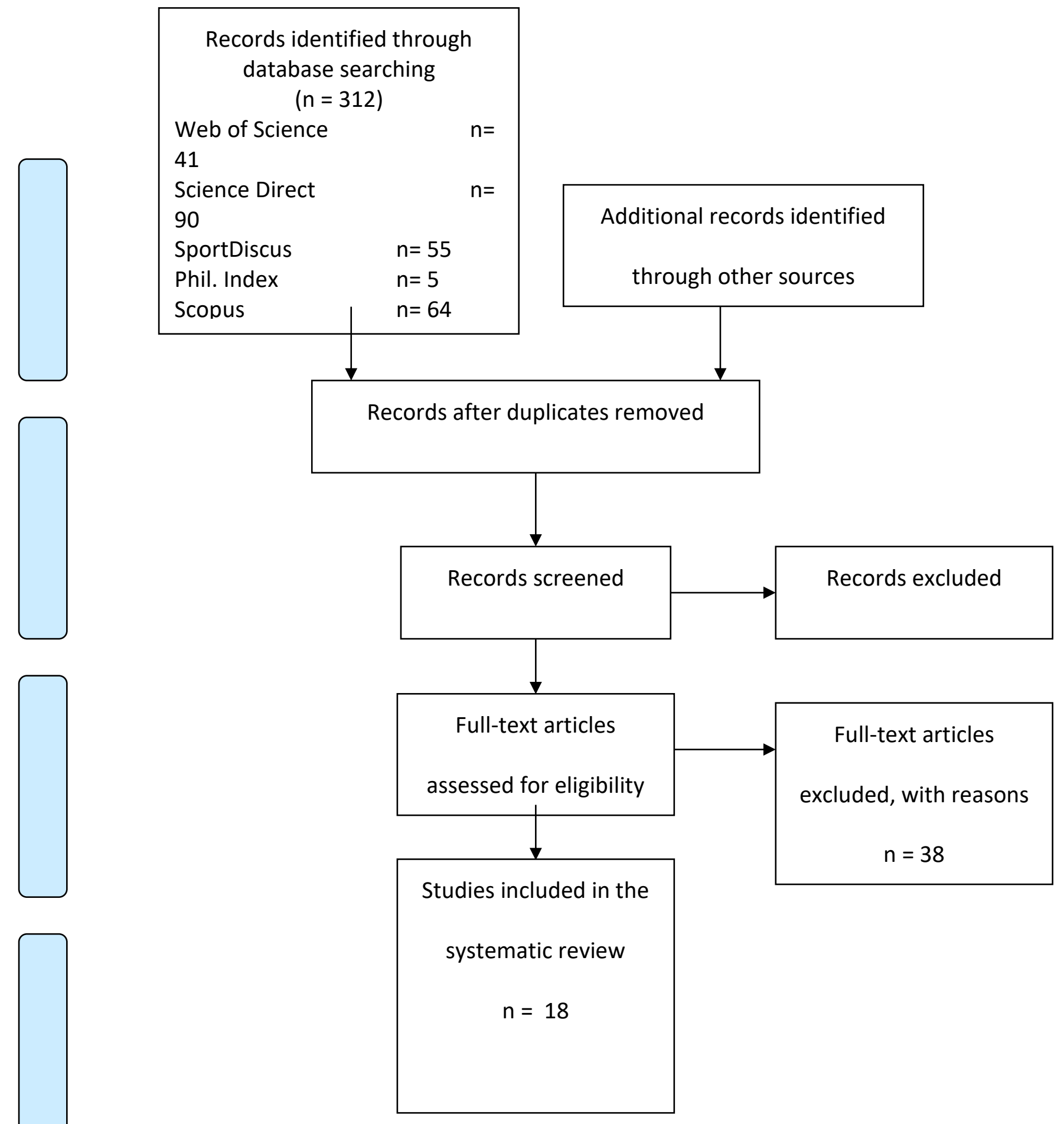

Figure 1 PRISMA flowchart of the search process 